\title{
Conceptual Framework of Effective Flood Forecasting and Early Warning System in Nepal: A Case Study of Koshi River Basin.
}

\author{
Mukesh Raj Kafle* \\ Department of Civil Engineering, Institute of Engineering, Pulchowk Campus, Lalitpur, Nepal \\ *Corresponding Author: Mukesh Raj Kafle, Department of Civil Engineering, Institute of Engineering, \\ Pulchowk Campus, Lalitpur, Nepal
}

\begin{abstract}
This study presents a conceptual framework of effective flood forecasting and early warning system in Nepal. The study is focused on Koshi River basin. In the proposed framework, HEC-HMS model can be applied for real flood forecasting purpose. The telemetry system and warning system should be developed for the operational forecasting system. Flood forecasting and warning center should be established in coordination of concerned authorities and institutions including DHM. For an effective flood forecasting and early warning system in Koshi basin, existing hydrological and rain gauge station network should be augmented. In hydrological station network, an additional station at Dudhkoshi upstream of the confluence of Dudhkoshi and Sunkoshi is proposed. Hampacuwar station of Sunkoshi should be operated to know the contribution of whole Sunkoshi and also to get the idea of contribution of tributaries downstream of the confluence of Dudhkoshi. Simle station of Arun near the confluence of Sunkoshi should be operated to get an idea of the contribution of whole Arun basin. Each additional rain-gauge station in the upper part of Tamakoshi, upper part of Dudhkoshi, upper part of Arun and upper part of Tamor is proposed. This method may be effective in the flood risk management in the Koshi alluvial fan and can be introduced in Himalyan Rivers in Nepal.
\end{abstract}

Keywords: flood forecasting, early warning system, HEC-HMS, conceptual framework, hydrological station, rain-gauge station.

\section{INTRODUCTION}

Nepal is a disaster prone country especially water induced disasters like floods, landslides, and glacial lake outburst floods (GLOFs). Around $24 \%$ of total population in Nepal are exposed to the threats annually which as a country ranks in $12^{\text {th }}$ position. (UNDP, 2004). Poor people, especially women, the elderly, and children, living in rural areas and on the floodplains are particularly vulnerable to flood hazards.

In the context of Nepal, five types of floods resulting loss of life and properties have been reported so far. Those are flash floods associated with i) extreme local scale precipitation (cloud burst) like in Lele area in 1981, Kulekhani area in 1993 and Syangja in 1998; ii) heavy monsoon precipitation at regional scale like in 1954 and 1955 in many parts of the country; iii) Glacial Lake Outburst Floods (GLOFs) like in Bhotekoshi/Sunkoshi in 1981 and Dudhkoshi in 1985; iv) Landslide Dam Outburst Floods (LDOFs) like in BudhiGandaki in 1967 and 1968, Balephi in 1982, Myagdi in 1988 and Larchakhola in 1996 and v) flood triggered due to failure of infrastructure such as dam and embankments like Koshi flood in 2008 and Bagmati flood in 1993. Nine events of disastrous flood triggered by the failure of infrastructures have been reported. In addition to these riverine floods, sheet flooding or inundation after heavy precipitation is common problem in lowland area in Inner Terai (BhitriMadesh) and Terai regions (Dixit 2003, Khanal 1996, 1997 and Khanal et al. 2007). On average, floods and landslides cause around 300 human losses per year, with economic damage exceeding USD 10 million (Khanal et al., 2007). Among major rivers, the impact, loss and damages by Koshi River in the past were observed significant (Kafle MR, 2019).

This loss of lives and property could have been reduced with an effective flood early warning system. Globally, the establishment of early warning and associated preparedness and response systems has helped to reduce the number of deaths from disasters over the last decade. Early warning systems promote the development and application of scientific knowledge, including improved information dissemination. Early warning systems can provide the necessary information and strategies to a wide 
array of actors to enable them to be proactive and better prepared for impending disasters. An effective system enables the concerned authorities and at-risk communities to know about the hazards at the locality, community vulnerabilities, and impending risk, to receive warning messages, and to mobilize their response capabilities to reduce risks. Early warning helps to reduce economic losses by allowing people to better protect their assets and livelihoods (UN, 2006). In Nepal, delivery of vital information to the public at risk has not always been successful. In many cases, local mechanisms for communicating risk and interpreting warnings remain weak (Lamichhane, 2011).

\section{REVIEW OF EXISTING FEWS IN NEPAL}

\subsection{Glacial Lake Outburst Floods Early Warning System for Tsho Rolpa}

The first flood early warning system in Nepal was established in 1990 to monitor glacial lake outburst flood (GLOF) downstream from Tsho Rolpa glacial lake in the Tama Koshi basin. This was one of the first GLOF early warning systems in South Asia. The system consisted of a set of sensors and automatic sirens linked to the water level in the lake. The sirens were established at 19 locations downstream, which was set to trigger an alert to warn communities downstream along the Rolwaling and Tama Koshi rivers when a certain level was reached in the lake. The extended line of sight (ELOS) with very high frequency radio communication system was used to warn the people residing riverbank and highly risked villages (Shrestha et al., 2008). The system worked for a few years, but inadequate operation and maintenance, vandalism, and others led to the system becoming defunct (Ives et al., 2010).

\subsection{Flood Early Warning System on the Bhote Koshi}

The early warning system in Bhote Koshi River, set up by Bhotekoshi Power Company (BKPC) consists of two sensor stations at the Friendship Bridge at Nepal- China border. It transmits a warning in the event of a GLOF to sirens, located downstream at the headwork and at Hindi village, and a warning cum monitoring station at the powerhouse. A spillway can be opened so that flow is no longer diverted for power production and the powerhouse is shut down (www.bhotekoshi. com.np/socialdetail). In the event of a GLOF or sudden spillway release, people are advised to move to a place at least $20 \mathrm{~m}$ above the normal riverbed level. However, the present dam is located only 6 $\mathrm{km}$ downstream from the Friendship Bridge and if a GLOF does occur, the warning system provides only five minutes lead-time to make the preparations (ICIMOD, 2012).

\subsection{Web-based Telemetry Flood Early Warning System at DHM}

Web-based telemetry system as early warning system in various rivers is developed by Department of Hydrology and Meteorology. The system provides real-time data and information on water levels and disseminates flood warnings to the various stakeholders. This system has been implemented in the Koshi basin. These hydrometeorological stations transmit real time data to the national and regional information system to enable timely warning. The water levels in the rivers are monitored using automatic sensors based on pressure and radar technologies and data is transmitted via the Internet using a combination of Code Division Multiple Access (CDMA) and Global System for Mobile Communication (GSM) technology. The Iridium satellite is included as a backup to transmit data when all other communication systems fail. Danger and alert levels have been established at each of the hydrological stations to trigger a warning based on a rise in water level. Moreover, DHM has installed more than 40 automatic stations throughout the country, which are providing real-time data through this web-based telemetry system (www.dhm.gov.np). However, there is no system for authoritative issuing of flood early warnings to those at risk.

\subsection{Community-based Flood Early Warning Systems}

Community based flood early warning systems was introduced in Nepal since 2002. In the beginning, observation towers were set up with a siren system to watch and warn communities of impending flood disasters (Practical Action, 2009). In the recent past, Practical Action and DHM in West Rapti basin had piloted an improved technology in the community based flood early warning system. Realtime information on water levels at the upstream gauging station provides information to communities to warn them of impending floods (Practical Action; Mercy Corps, 2012). The high water level that occurred in the West Rapti basin in 2012 was successfully communicated to the communities and timely action was taken (Gautam and Phaiju, 2013). Moreover, community-based flood early warning system has also been established in Banke and Bardia districts. In this model, communities are considered to be an integral part of the system and participate in risk assessment, communication and dissemination, and immediate response activities. 


\section{StUdy AREA}

SaptaKoshi River is popularly known as Koshi in Nepal and India. After the confluence of three rivers Arun, Sun Koshi and Tamor at Tribeni in Sunsari District, Koshi zone of Nepal, the river is named as Sapta Koshi, meaning a river with seven major tributaries. Among the seven rivers: Indrawati, Sunkoshi, Tamakoshi, Likhu and, Dudh Koshi, are the major tributaries of Sunkoshi. Arun and Tamor are the remaining two major tributaries. The Koshi River is a trans-boundary river originating in Tibet (China) and flowing through Nepal and India. It is one of the largest tributaries of the Ganges River. The entire Koshi River basin up to its confluence with the Ganges in India has a catchment area of $69,300 \mathrm{~km} 2$, out of which, 29,400 km2 lies in China; 30,700 km2 in Nepal and 9,200 km2 in India. About 5,700 sq. km. area of the catchment is under glaciers. The Koshi River basin as a tributary of Ganges is shown in (Figure 1-1)

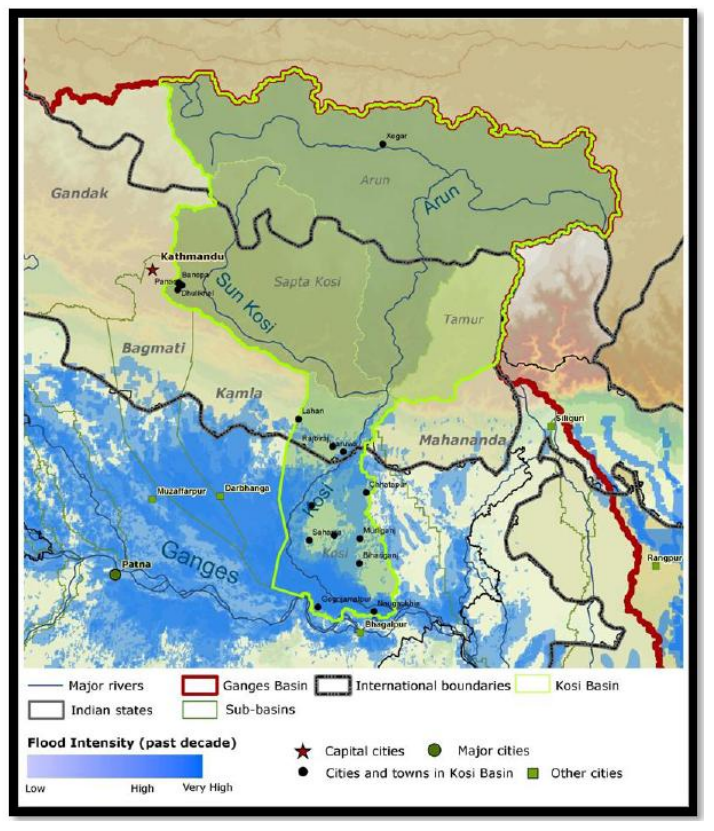

Figure1-1. Koshi basin as a tributary of Ganges

At present, 49 rainfall stations and 12 gauging stations are considered for the precipitation and discharge measurement respectively in the basin (Figure 1-2,1-3). The most of the rainfall stations are located in the mid and lower part of the basin. The upper high mountain part (snow covered area) is not easily accessible. The contribution of major sub-basins can be assessed from the data from these stations. Station nos. 600.1 and 600.4 represent the flow at two locations of Arun Basin. The discharge at two locations of Tamor is represented by station nos. 684 and 690 . The contribution from Tamakoshi, Likhu and Dudhkoshi is represented by stations 647, 660 and 670 respectively. The flow at various locations of Sunkoshi is represented by stations 610,630,652 and 680. The outlet station of the basin is Chatara station (station no. 695).

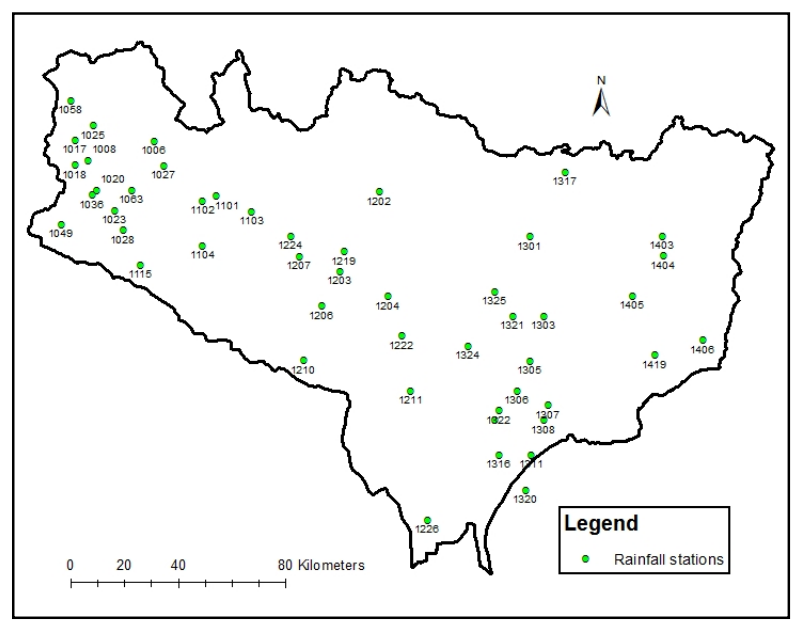

Figure1-2. Location of rainfall stations in the Koshi basin 


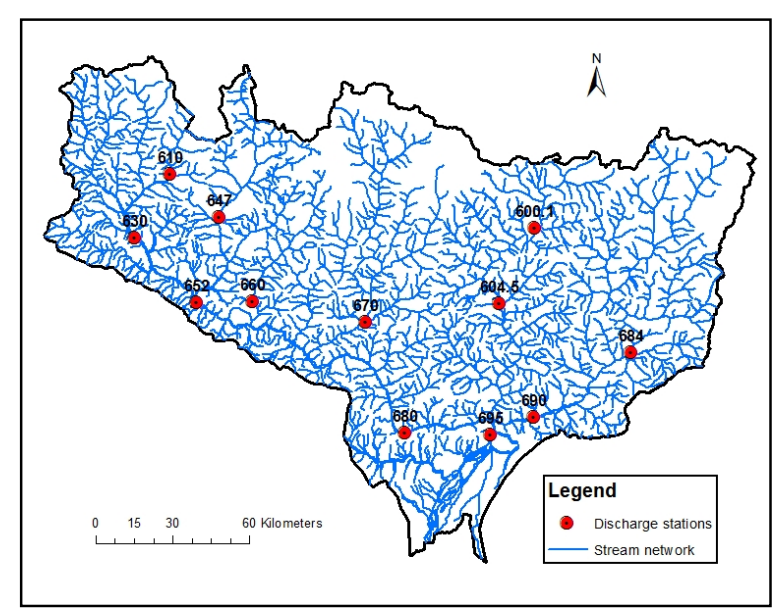

Figure1-3. Drainage network of Koshi basin with hydrological stations

\section{Proposed Frame Work of EfFective FEWS in Koshi Basin}

\subsection{Effective Early Warning System}

A complete and effective early warning system consists of four components (ISDR, 2010; Basher R, 2006)

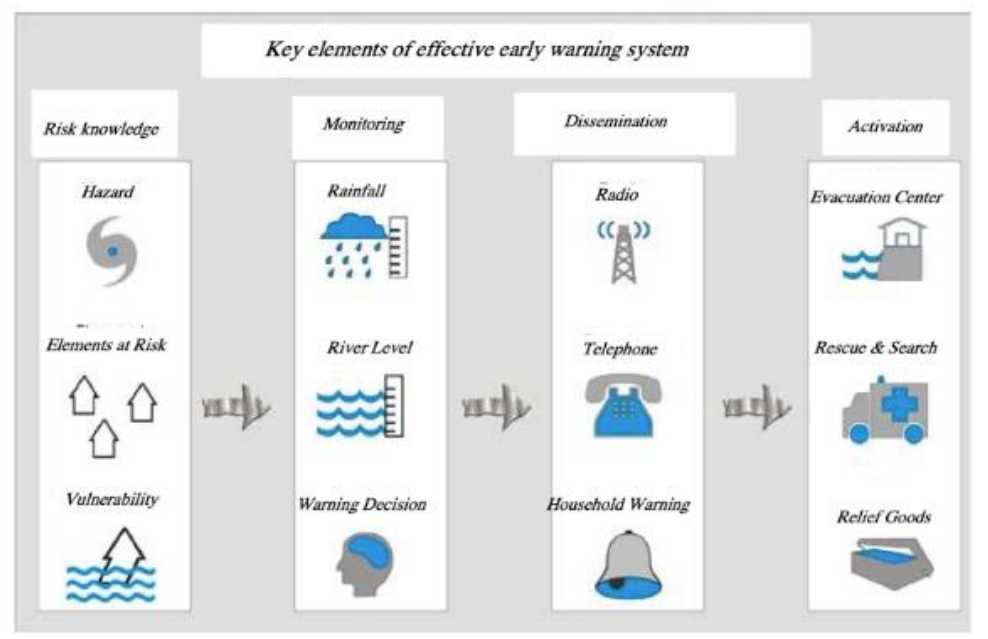

Figure1-4. Four components of early warning system (Neussner, 2009)

\subsubsection{Risk Assessment}

Knowledge and assessment of risks is the key component of an effective early warning system. It comprises hazards and vulnerabilities at a particular location. Risk assessment deals with systematic collection and analysis of data and should consider the dynamic nature of hazards and vulnerabilities. Those vulnerabilities arise from processes such as urbanization, rural land-use change, environmental degradation and climate change. Identification of vulnerable areas and preparation of risk maps is necessary to concentrate early warning to particular location. Assessment of warning and danger level is necessary to make decision on warning and to guide preparations for disaster prevention and responses.

\subsubsection{Monitoring}

This is the core of the system that entails continuous monitoring of hazard parameters (flood level, rainfall etc.). These parameters are essential to generate accurate warnings in a timely fashion. There should be a reliable forecasting model for predicting and forecasting hazards and the warning system should operate round the clock.

\subsubsection{Dissemination}

Dissemination and communication components deliver the timely warnings to the people at risk. The messages should be simple, understandable to the people of community. Regional, national and 
community level communication systems must be pre-identified and appropriate authoritative voices established. The use of multiple communication channels is necessary to ensure as many people as possible are warned, to avoid failure of any one channel, and to reinforce the warning message.

\subsubsection{Activation}

Once flood warning is received from the warning system; the response system comes into action by transmitting the information to the competent authorities (local or others). Those authorities take preventive action and pass the warning to the local people who can react within the lead-time. It is essential that communities understand their risks; respect the warning service and know how to react. Education and preparedness programs play a key role. The community should be well informed on options for safe behaviour, available escape routes, and how best to avoid damage and loss to property.

\subsection{Forecasting Model}

The calibrated HEC-HMS model will be useful for flood forecasting. The output of the model provides the flow at the outlet of each sub-basin. The time of travel of wave from the confluence with the main stream to a designated point downstream (Chatara) should also be known. The time of travel can be estimated by using the historical flow hydrographs (shorter duration e.g. hourly) at two ends or by running hydrodynamic model. With the calibration and validation of model with historical timeseries, the parameters of the models are determined. The next step is the application of the developed model for flood forecasting at Chatara of Koshi River basin. Acquisition of precipitation data in real time is pre-requisite for establishing flood-forecasting system. Therefore, the rainfall stations from which the data can be received in real-time or near real-time are selected. Forecast variable is discharge or water level at Chatara. With the observed rainfall data until time $t$ and rainfall forecast data, the discharge will be forecasted for next 24 hours. The implementation of flood forecasting system will follow the steps- (i) Entry of input data obtained in real time (ii) Model execution (iii) Updating of output.

\subsection{Hydrologic Station Network}

Among the 12 hydrological stations (Figure 1-3), station no. 680 is not in operation currently. Station no. 652 is close to the confluence of Tamakoshi. As the river length of Likhu from Sangutar to confluence is about $15 \mathrm{~km}$ and the contribution of Likhu to mean annual flow at chatara is not high, there is no need of additional hydrological station at the confluence of Likhu and Sunkoshi. An additional station at Dudhkoshi upstream of the confluence of Dudhkoshi and Sunkoshi is needed to know the contribution of Dudhkoshi basin. Hampacuwar station of Sunkoshi should be operated to know the contribution of whole Sunkoshi and also to get the idea of contribution of tributaries downstream of the confluence of Dudhkoshi. Simle station of Arun near the confluence of Sunkoshi should be operated to get an idea of the contribution of whole Arun basin. In case of Tamur, the basin area downstream of Mulghat is not large. Therefore, additional station is not necessary downstream of Mulghat. The hydrological stations proposed for real time flood forecasting model are presented in Table 1-1.

Table1-1. Proposed Hydrological station network for real time flood forecasting

\begin{tabular}{|l|l|l|l|l|}
\hline S.N & Station & River & Location & Remarks \\
\hline 1 & 600.1 & Arun River & Uwagaon & Existing \\
\hline 2 & 604.5 & ArunRiver & Turkeghat & Existing \\
\hline 3 & 606 & Arun River & $\begin{array}{l}\text { Simle (near confluence } \\
\text { of Sunkoshi) }\end{array}$ & $\begin{array}{l}\text { Existing, but not in operation, To } \\
\text { be operated }\end{array}$ \\
\hline 4 & 610 & BhoteKoshi & Barabise & Existing \\
\hline 5 & 630 & SunKoshi & Pachuwar-Ghat & Existing \\
\hline 6 & 647 & TamaKoshi & Busti & Existing \\
\hline 7 & 652 & SunKoshi & Khurkot & Existing \\
\hline 8 & 660 & Likhu & Sangutar & Existing \\
\hline 9 & 670 & DudhKoshi & Rabuwa-Bazar & Existing \\
\hline 10 & & DudhKoshi & $\begin{array}{l}\text { Upstream of } \\
\text { confluence of Sunkoshi }\end{array}$ & Proposed \\
\hline 11 & 681 & Sunkoshi & Hampachuwar & $\begin{array}{l}\text { Exiting, but not in operation, To be } \\
\text { operated }\end{array}$ \\
\hline 12 & 684 & Tamur & Majhitar & Existing \\
\hline
\end{tabular}


Conceptual Framework of Effective Flood Forecasting and Early Warning System in Nepal: A Case Study of Koshi River Basin.

\begin{tabular}{|l|l|l|l|l|}
\hline 13 & 690 & Tamur & Mulghat & Existing \\
\hline 14 & 695 & Sapta Koshi & Chatara-Kothu & Existing \\
\hline
\end{tabular}

\subsection{Rainfall Station Network}

Based on the contribution of tributaries to the outflow at Chatara and the areal coverage, the existing stations are proposed to upgrade for real time transmission of rainfall data to forecasting center (Table 1-2). Stations 1008, 1023, 1027, 1028 and 1058 represent Sunkoshi upper part. Stations 1102 and 1104 represent Tamakoshi. Stations 1049, 1103 and 1115 represent Sunkoshi mid part. Station 1224 represent Likhu. Stations 1202, 1204, 1207, 1219 represent Dudhkoshi. Stations 1210 and 1222 represent Sunkoshi lower part. Stations 1301, 1317 and 1325 represent Arun upper part. Stations 1305, 1306, 1321 represent Arun lower part. Stations 1307, 1403, 1405, 1419 represent Tamor. Each station in the upper part of Tamakoshi, upper part of Dudhkoshi, upper part of Arun and upper part of Tamor are proposed to add.

Table1-2. Proposed rain gauge station network for up gradation

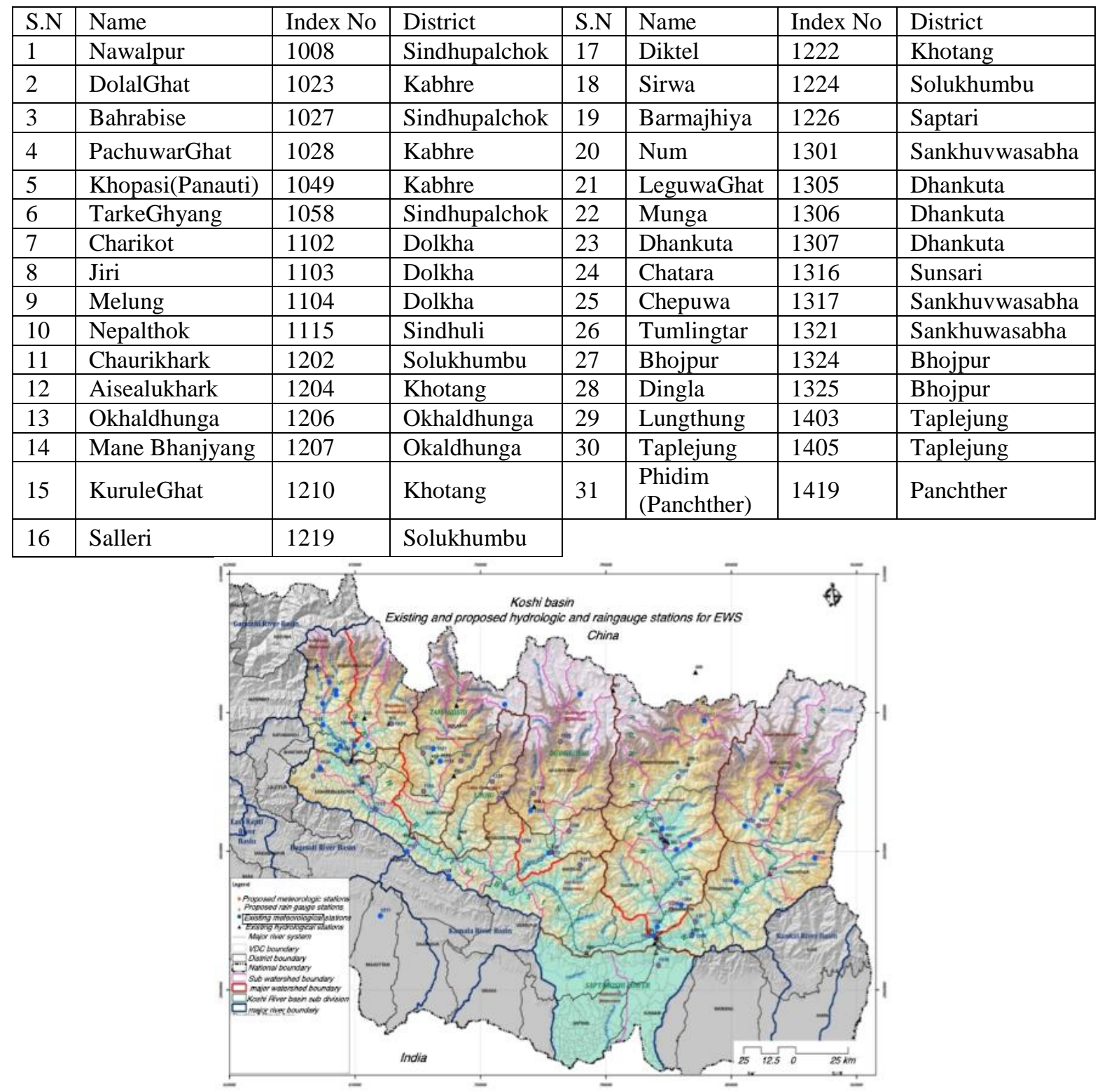

Figure1-5. Location of existing and proposed stations for EWS

\subsection{Real Time Database Management System}

An operational flood forecasting and warning system requires the following:

- A real-time data collection and processing subsystem for receiving and processing the relevant hydrological and meteorological information. This will include meteorological information, the 
water level and discharge data at appropriate gauged sections in rivers and from reservoirs, and also soil moisture measurements and a database management system. This may involve manual or automatic recording gauges, terrestrial data-collection platforms, ground based radars, satellites, airborne sensors and extensive use of GIS and data management system to present such information in ready-to-use format;

- Outputs of a numerical meteorological forecasting subsystem, that is, numerical weather prediction (NWP) models for meteorological inputs, for example the quantitative precipitation forecast (QPF), during the required lead time of the flood forecasting model;

- A subsystem to combine optimally the data from various sources and to provide a feedback mechanism for the recalibration of measuring tools and techniques, and for the initialization of model error correction;

- A hydrological modeling subsystem, embedded in a user-friendly interface, to estimate the total discharge at the catchment outlet, at the required time intervals, along with a corresponding statement of uncertainty having option to run many hydrological models from the same user interface;

- A subsystem comprising a channel routing model to estimate the movement of the flood wave along the channel, the water levels, discharges, the effects of dyke breaches and reservoir operation, and the interaction with the flood plain and flooded areas, giving a flood inundation forecast;

- An error correction subsystem incorporating an algorithm to improve the estimates of discharge based on recent feedback from river-gauge data;

- Appropriate decision support systems, producing forecast details at various levels and map forecasts showing flood inundation in real time.

\subsection{Early Warning System}

\subsubsection{Telemetry Systems}

Telemetry system is proposed for the best means of communication. It detects, collects, and processes physical data of one form or another at a given site, and then relaying this data to a receiving station at another site where the data can be recorded and analyzed. The telemetry system consists of components for the measurement of the quantity, storing them into some storage device (called data logger) and then relaying that data to the monitoring point through any means of communication. As we are concerned with real time data acquisition, the proposed means of communication will be available round the clock

\subsubsection{Institutional Aspect}

An operational Flood Forecasting and Early Warning Centre is proposed to establish at the central level with branch office Koshi basin. . It will have to be a fully equipped and manned organization, which will have multi-stage and multi-institutional involvement with effective communication and networking. The two major functions of the centre should be forecasting of the probable flood with sufficient lead time based on telemetrically obtained field data, and dissemination of warning to the affected people through available communication system. Department of Hydrology and Meteorology (DHM) will handle the first part whereas second part jointly by DHM and Ministry of Home Affairs (MoHA).

\subsubsection{Equipment}

The manually operated existing equipment in hydrological and meteorological stations in Koshi basin will be additionally instrumented with sensors. For flood forecasting purpose, the hydrometric or meteorological stations should be selected for additional instrumentation. For this purpose the nine stations selected by the HKH-HYCOS project will be considered as the primary stations. As the larger the number of stations predicts more reliable results, all of the existing stations will be operated effectively by connecting to the telemetric system. However, the flood prediction model can filter the use of the data at any time at the discretion of the operator of the model. All existing climatological stations will be equipped with automatic weather station (AWS), with sensors to record the parameters -rainfall, temperature, relative humidity, barometric pressure, wind speed and wind direction. An AWS will typically consist of a weather-proof enclosure containing the data logger, 
rechargeable battery, telemetry and the meteorological sensors with an attached solar panel or wind turbine and mounted upon a mast. The specific configuration may vary due to the purpose of the system.

\subsubsection{Power Supply}

The main power source for an automatic weather station is usually one or more solar panels connected in parallel with a regulator and one or more rechargeable batteries. As a rule of thumb, solar output is at its optimum for only 5 hours each day. The output from the solar panels may be supplemented by a wind turbine to provide power during periods of poor sunlight, or by direct connection to the local electrical grid. The wind turbine option may be valid in some of the windy locations in future. But for the present, the stations will be supplied with the existing power grid, which may be either a national grid or from a local supplier as the case may be. Since, the grid power has no guarantee for uninterrupted power supply, for all stations connected to telemetry, 24-hour uninterrupted power will be guaranteed from solar panels.

\subsubsection{Community Outreach and Response Mechanism}

Effective and efficient early warning system requires involvement of communities. Several factors influence a community's decision to engage in flood early warning system. Those factors include hydrologic characteristics of the area; frequency of flooding, community's interest and awareness, flood loss potential (hazard vs. damage curve), warning time vs. benefits and cost of putting-up a system. Local Government Unit (LGU) should play a key role in community outreach. The key to facilitating the community's participation is rapport. The largely intuitive and indigenous knowledge of communities is equally important and reliable as its technical and scientific expertise. Therefore, consultation with the LGUs and certain members of the community is a prerequisite prior to commencement of the community outreach activities.

Operation and maintenance of early warning system (EWS) is often a bottleneck for sustainability low cost solutions and technical designs must reflect realistic budgetary commitment. Operational planning includes mock drills, community preparedness and programs and all components requiring maintenance and system calibration and updating by community or individual over time. These decisions and actions ultimately determine the system's success or failure. The message content of the warning needs to be as simple as possible for end-users and to be provided in a timely manner to facilitate appropriate action. Message delivery systems must be as cost effective, replicable and simple as possible. False alarms are risks that must be acknowledged and the credibility of the message is crucial for acceptance of warning by the community.

\subsection{Danger Level at Chatara}

According to danger level assessment study carried out by Department of Hydrology and Meteorology (DHM), there is no inundation to the flood plain up to DHM gauge height of $5.6 \mathrm{~m}$ at Chatara. So, this is the threshold value above which the flooding begins. Hence, the water level at 5.6 $\mathrm{m}$ is marked as warning level. Gauge height exceeding $6.8 \mathrm{~m}$ causes flooding in the settlements, the inundation depth being greater than $1.5 \mathrm{~m}$. Therefore; gauge height of $6.8 \mathrm{~m}$ is demarcated as danger level. Fig. 1-3 shows the corresponding gauge heights of maximum instantaneous discharge in comparison to the warning level and danger level at the station. It can be seen that the warning level is almost always exceeded and annual instantaneous maximum floods also exceed the danger level frequently.

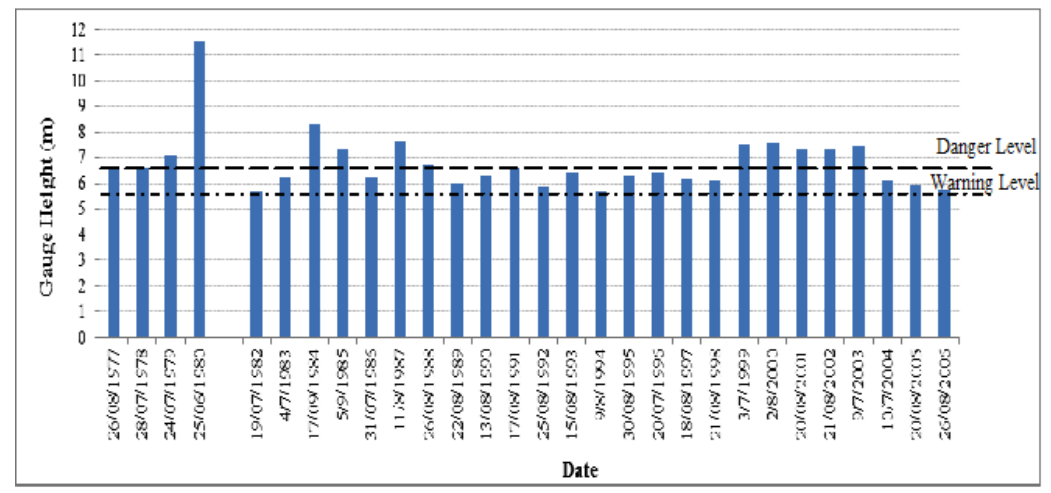

Figure1-5. Annual instantaneous maximum flood gauge height with warning and danger level (Chatara) 


\section{CONCLUSION}

Flood forecasting and early warning systems require contributions from a wide range of actors and institutions, including local communities, union government, and regional organizations. It is an effective non-structural tool of flood risk management. HEC-HMS model can be applied for real flood forecasting purpose. The telemetry system and warning system should be developed for the operational forecasting system. Flood forecasting and warning center should be established in coordination of concerned authorities and institutions including DHM. For an effective flood forecasting and early warning system in Koshi basin, existing hydrological and rain gauge station network should be augmented. In hydrological station network, an additional station at Dudhkoshi upstream of the confluence of Dudhkoshi and Sunkoshi is needed to know the contribution of Dudhkoshi basin. Hampacuwar station of Sunkoshi should be operated to know the contribution of whole Sunkoshi and also to get the idea of contribution of tributaries downstream of the confluence of Dudhkoshi. Simle station of Arun near the confluence of Sunkoshi should be operated to get an idea of the contribution of whole Arun basin. The existing rain gauge stations should be upgraded for real time transmission of rainfall data to forecasting center. Each station in the upper part of Tamakoshi, upper part of Dudhkoshi, upper part of Arun and upper part of Tamor is proposed to add. This method may contribute better in the flood risk management in the Koshi alluvial fan thus reducing flood damages including loss of lives and property.

\section{REFERENCES}

[1] Lamichane, R (2011) People's perception in early warning systems: A case study of Bhandara VDC Padariya-7 in Chitwan district, Nepal. MA thesis, BRAC University, Dhaka, Bangladesh

[2] Practical Action; Mercy Corps (2012) Community based early warning systems in South and South East Asia: Best practice \& learning. Kathmandu, Nepal: Practical Action; Mercy Corps

[3] Practical Action (2009) Early warning saving lives. Kathmandu, Nepal: Practical Action

[4] Neussner, O (2009) Manual: Local flood early warning systems - Experiences from the Philippines. Leyte, Philippines: Deutsche Gesellschaft für Technische Zusammenarbeit (GTZ) GmbH

[5] UNDP (2004) Reducing disaster risks: A challenge for development. New York, USA: UNDP

[6] Khanal, NR; Shrestha, M; Ghimire, M (2007) Preparing for flood disasters: Mapping and assessing hazard in the Ratu Watershed, Nepal. Kathmandu, Nepal: ICIMOD

[7] UN (2006) Global Survey of early warning systems: An assessment of capacities, gaps and opportunities towards building a comprehensive global early warning system for all natural hazards. New York, USA: United Nations

[8] Kafle MR (2019) Rainfall-Runoff Modelling of Koshi River Basin Using HEC-HMS. J Hydrogeol Hydrol Eng 8:1.

[9] HEC-HMS and HEC-RAS, URL: http://www.hec.usace.army.mil/

[10] Department of Hydrology and Meteorology (2010), Determination of Flood Danger Level in Flood Forecasting Stations.

Citation: Mukesh Raj Kafle, " Conceptual Framework of Effective Flood Forecasting and Early Warning System in Nepal: A Case Study of Koshi River Basin.", International Journal of Research in Environmental Science (IJRES), vol. 5, no. 4, pp. 43-51, 2019. Available: DOI: http://dx.doi.org/10.20431/2454-9444.0504003

Copyright: (C) 2019 Authors. This is an open-access article distributed under the terms of the Creative Commons Attribution License, which permits unrestricted use, distribution, and reproduction in any medium, provided the original author and source are credited. 